\title{
LA REFORMA PROCESAL PENAL CHILENA: NUEVO MARCO MEDICO-LEGAL DEL EJERCICIO DE LA RADIOLOGIA*
}

\author{
Drs. Juan Ritz $P^{(1)}$, César García $M^{(2)}$, Dulia Ortega $T^{(3)}$
}

1. Director de la Administración delegada de Accidentes del Trabajo y Enfermedades Profesionales Pontificia Universidad Católica de Chile. Presidente de la Sociedad Chilena de Medicina Legal, Ciencias Forenses y Ciencias Criminalísticas. Perito médico de la Corte de Apelaciones Santiago.

2. Departamento de Imágenes. Departamento de Imagenología Clínica Alemana de Santiago.

3. Hospital Clínico Universidad de Chile.

\begin{abstract}
Recently adopted laws related to modifications in penal procedures have introduced major changes in the management of conflicts in healthcare. Changes, affecting radiology, include previous outcourt solutions, such as mandatory arbitrage and/or mediation or, if they fail, a medical malpractice lawsuit is filed, there are new ways for agreements: reparatory settlements, alternative judicial solutions, or, the last instance, a new kind of trial: public, oral, with the prosecution, defending and sentencing functions clearly divided. Changes in the scenario do not excuse us to adopt and implement actions to prevent medical error in our practices to reduce, conflicts and lawsuits. It will result in better medical attention.
\end{abstract}

Key words: Conflict of Interests, Jurisprudence, Medical errors.

Resumen: La Reforma Procesal Penal y la Reforma de Salud, irrumpen en un escenario con aumento de la tribunalización de conflictos en la atención médica, impulsados por cambios en las expectativas de la sociedad, y de los cuales los radiólogos no estamos exentos. Las principales modificaciones son las soluciones destribunalizadas de conflictos médicos por mediación o arbitraje $y$, en las querellas, acuerdos reparatorios o la realización de un nuevo juicio oral y público, con división de las tareas de investigación, defensa y sentencia. Evitar llegar a la representación supone adoptar las medidas necesarias para gestionar los errores médicos, para disminuirlos y reducir la conflictividad y la tribunalización.

Palabras clave: Conflictos de interés, Errores médicos, Jurisprudencia.

\section{Objetivos}

Dar a conocer los aspectos más importantes en un nuevo marco médico legal para el ejercicio de la profesión médica, con especial referencia a la

Ritz J. La Reforma procesal penal chilena: Nuevo marco médico-legal del ejercicio de la radiología. Rev Chil Radiol 2005; 11: 142-149.

Correspondencia:jritz@med.puc.cl radiología; analizar las causas más probables de la mayor tribunalización de los conflictos médicos, considerando aspectos relacionados con los pacientes, los médicos y la sociedad; revisar las posibles medidas para la prevención de la conflictividad y de la tribunalización, basadas en la prevención del error.

\section{Introducción}

La Reforma procesal penal (RPP) trata de cumplir con aspiraciones largamente esperadas, en el sentido de desencadenar una modernización de los procedimientos de una justicia excesivamente lenta, misteriosa, omnímoda, inquisitiva, en la cual se presume la culpabilidad hasta que el acusado demuestre su inocencia. En esencia se trata, de una modernización con separación de la parte acusadora, defensora y del juez que dicta la sentencia, lo que garantiza una mayor agilización, rapidez, independencia, una mejor investigación y evaluación de los hechos y acciones investigados, con un amplio abanico de posibilidades de solución de conflictos y con un cambio fundamental: se presume la inocencia del acusado hasta que se pruebe su culpabilidad.

Su accionar alcanza todos los ámbitos de la nación, pero nuestro interés es revisar cómo este nuevo escenario judicial afectará a los médicos que son convocados a los Tribunales de Justicia en diversas calidades ya sea como testigo, experto, perito o imputado. Está fuera del objetivo de esta publicación un análisis exhaustivo de los aspectos jurídicos y legales de esta RPP, los que pueden ser revisados en la literatura pertinente ${ }^{(1)}$.

\section{Interés en la RPP}

Nuestro interés está comprometido con los profundos cambios que han ocurrido en el conjunto de la sociedad, en los últimos treinta años, relacionados con diversos factores, como la percepción y

*Artículo basado en la conferencia «Reforma Procesal Penal y los Radiólogos» dictada por el Dr. J. Ritz P. en el curso «Actualidades en Radiología». Santiago. Hotel Hyatt. Marzo 2005, posteriormente completada y revisada por el autor. 
expectativas de la comunidad frente a la atención médica, la explosión tecnológica incluidos los extraordinarios avances en medicina, la revolución de las tecnologías de la información y su incorporación a la atención médica, la irrupción de la bioética incluyendo los derechos de los pacientes, la gestión en la atención médica, con la marginación de los profesionales de las decisiones en política y dirección sanitaria, etc ${ }^{(2)}$.

Los cambios sociales modificaron el entorno donde se desarrollaba el ejercicio de la medicina, con la progresiva desaparición del ejercido privado y de la libre elección, la aparición de grandes corporaciones o del Estado mismo que toman el control de la gestión de la atención médica, tanto en sus aspectos de afiliación, cobertura, prestación y administración del sistema, con criterios fundamentalmente de mercado. No queremos con esto, afirmar que no sea necesario cuidar los siempre escasos recursos de que dispone la salud, sino que estos criterios no deben entrar en conflicto con el profesionalismo de la atención médica, que debe poner en primer lugar el beneficio del paciente por encima de cualquier otra consideración. Del mismo modo, estos mismos entes corporativos o el Estado contratan a los médicos en condiciones salariales desmedradas y les imponen una carga de trabajo que en ocasiones entran en conflictos con nuestro profesionalismo y la calidad de la atención brindada ${ }^{(3)}$.

Estos factores han terminado por erosionar de un modo importante la relación médico-paciente, la que se ha horizontalizado, con gran interés del paciente en tomar parte de su proceso de atención. Este cambio muy positivo, que reconoce la autonomía del paciente y su competencia para tomar decisiones directamente relacionadas con los procedimientos diagnósticos y terapéuticos que se le proponen, al estar dándose en términos confrontacionales basados en la lógica de la relación cliente-prestador, ha dañado, la atención médica en sus aspectos humanitarios: comunicación y empatía, calidez, interés en el paciente y su entorno. Aun cuando los pacientes no cuestionan las habilidades técnicas ni los conocimientos de sus médicos, ven un desarrollo tecnológico sin precedentes en el diagnóstico y tratamiento de las enfermedades, muchas veces insuficientemente comprendido incluso por los mismos médicos, y poco explicados en cuanto a sus reales resultados, limitaciones, contraindicaciones, complicaciones y alternativas a su uso, produciendo la sensación errónea en los pacientes de que los «malos» resultados diagnósticos o terapéuticos son siempre debidos a fallas del médico y su equipo, a quienes hay que exigirles explicaciones y eventuales reparaciones por medio de los tribunales de justicia si fuere necesario, y no a una razón ligada a las condiciones previas del paciente, efectos secundarios de la terapéutica y potenciales complicaciones o resultados inesperados que están ligados al riesgo inherente a toda acción médica ${ }^{(4)}$.

El entorno actual ha producido en los médicos una sensación de descontento creciente hacia el modo cómo realiza su trabajo, con poco tiempo dedicado al paciente, lo que se traduce en una sensación de crisis con indefensión tanto de las personas con relación a sus problemas de salud como de los médicos en su ejercicio profesional, incluyendo la exposición pública de supuestos errores en los medios de comunicación que así como resaltan curas milagrosas en diferentes lugares del planeta, destacan los supuestos errores garrafales en hospitales y clínicas nacionales. Qué duda cabe, las querellas por «Mala Praxis» son noticias que aumentan el tiraje de diarios y "rating" de noticieros $^{(5,6)}$.

\section{¿Qué consecuencias han tenido estos cambios en nuestro país?}

Si pudiéramos resumir estas sensaciones de pacientes y médicos podríamos decir que las personas naturales, la gente, tienen poca confianza en el sistema de prestaciones de salud y, a su vez, los médicos sienten la necesidad de una validación permanente frente a los pacientes e instituciones que les producen una sensación de indefensión contractual y legal( ${ }^{(7)}$.

\section{¿Qué ha sucedido con la Radiología y los Radiólogos?}

Los radiólogos están incluidos en este contexto general, pero como especialistas de apoyo, tienen algunas particularidades que les son propias. Son un grupo relativamente reciente en la medicina, y en la práctica diaria tienen, en general, poco contacto directo con los pacientes. El hábitat ha cambiado desde la década de los sesenta, caracterizada por modalidades de tecnología primaria, sin equipamiento costoso, con pocas opciones de apoyo real al diagnóstico clínico, con un estrecho rango de diagnósticos exclusivamente morfológicos, en un ambiente laboral de alta consideración social, hacia otro que en la actualidad se caracteriza por grandes avances tecnológicos, estudios de imagen funcionales, costos incontenibles, con un amplio rango de diagnósticos e intervencionismo, gran carga de trabajo no siempre bien remunerado y, crítica social abierta. Las imágenes pasaron de la sala de rayos al lado de la cama del enfermo con los radiólogos integrados con el equipo de médicos tratantes ${ }^{(8)}$.

La mejoría en los diagnósticos, apoyada en la incorporación de tecnología de punta incluidas las imágenes, ha conducido a un aumento progresivo en los costos, con encarecimiento de la atención, con aplicación de políticas que restringen el uso de algunos de estos avances o simplemente la carencia absoluta de ellos para ciertos sectores de nuestra población, introduciéndose un factor de distanciamiento y deshumanización de nuestra atención que ha ido produciendo un deterioro de la imagen del radiólogo y de la radiología. Hemos además puesto un poco en el limbo nuestro objetivo primordial que es el paciente y por ello debemos tener muy claro que la atención de éste, a través de las imágenes, no 
es una excusa para que distanciamiento o deshumanización ocurran ${ }^{(9)}$.

\section{Tribunalización de los conflictos médicos}

El principal resultado de estos cambios es el deterioro de la relación médico-paciente, con generación de una desconfianza hacia los sistemas de atención médica, con pérdida del prestigio profesional, que se traduce en un aumento explosivo de la tribunalización de los conflictos. Enfermos disconformes o que se sienten en un callejón económico sin salida, piensan en demandar a sus médicos. Consideremos además que las querellas por «Mala Praxis» son económicamente atractivas para los abogados, constituyendo un campo de especialización en dicho ejercicio.

Las cifras del Instituto Médico Legal (IML) muestran un incremento de un $415 \%$ en el número de casos ingresados a pericia por demandas de responsabilidad civil médica en el período que va desde 1991 al 2001. Es importante consignar que en cifras de FALMED, del año 2001, se confirma dicho crecimiento, destacando que la mayoría de los resultados de las demandas son favorables a los médicos. Sin embargo, un $15 \%$ del total de dichas demandas, periciadas en el IML, son acogidas por negligencia, imprudencia o impericia(10,11).

Los radiólogos como grupo, son poco demandados y las demandas interpuestas han sido por motivos como: error diagnóstico, complicaciones en el uso de medios de contraste, complicaciones de procedimientos intervencionales, «fallas logísticas», o error de procedimiento ${ }^{(12,13)}$.

Un Tribunal puede citar al médico en calidad de testigo, experto, perito o imputado.

1. Testigo: La calidad de testigo significa declarar en un hecho que está siendo investigado. Este testimonio trata de aclarar la participación en un acto médico, en el contexto de una investigación judicial, en la cual otra persona, que puede ser un colega, ha sido demandado. Los radiólogos por regla general testimonian, sobre imágenes con frecuencia efectuadas por ellos mismos o procedimientos implicados en el hecho investigado y su relación a importancia y conductas terapéuticas que pudieron haber generado.

La ficha clínica es el documento fundamental, que debe contener toda la información médica de un paciente. Constituye un medio de prueba y sirve de base para lo que declaran los médicos citados a un Tribunal, sea en calidad de testigos, expertos, peritos o en condición de imputados ${ }^{(14)}$.

El informe radiológico merece iguales consideraciones que la ficha clínica, pues es para los radiólogos un documento fundamental, producto comunicacional de su trabajo, elaborado sobre la base de normas o estándares que resume el proceso de elaborar una impresión diagnóstica. Es a la vez un medio de prueba de primordial importancia. Las imágenes sobre las que debemos declarar son un examen que ha sido interpretado por un radiólogo para deducir de él una impresión diagnóstica que puede reflejar certeza, duda o posibilidad y por ello debemos ser cuidadosos en no emitir juicios taxativos sin dejar posibilidad para diagnósticos diferenciales, limitaciones del examen empleado o la necesidad de otras modalidades de imágenes, ubicando todo en el contexto del momento y lugar en que se efectuó la atención ${ }^{(15)}$.

2. Experto: La calidad de experto corresponde a un médico llamado al tribunal por su conocimiento en un área determinada del saber médico o por ocupar puestos de liderazgo en Universidades o Sociedades Científicas Nacionales. Su testimonio u opinión debe efectuarse considerando la «lex artis medicae», el estado del arte basado en la mejor evidencia disponible, y la circunstancia, el tiempo y el lugar del hecho investigado, considerando que al médico se le exige actuar de acuerdo al conocimiento promedio del arte o especialidad de su práctica, es decir hacer lo que cualquier otro habría hecho o dejado de hacer si hubiese estado en su lugar. Con frecuencia los tribunales, o los abogados, efectúan consultas fuera de contexto, que no deberían responderse sin pedir antecedentes sobre las circunstancias y el lugar en que ocurrieron los hechos, y sólo entonces emitir un pronunciamiento.

A los radiólogos se nos solicita en esta calidad la opinión sobre exámenes complejos, o si las opiniones de los testigos son muy contradictorias. Si es necesario, en estos casos, previa consulta al juez, debemos asesorarnos por los especialistas más connotados en esa área, antes de emitir nuestra opinión que por regla general es una opinión o impresión diagnóstica y las condiciones en que se hizo o dejó de hacer un acto radiológico.

3. Perito: La calidad de perito es la de un médico inscrito en un registro de peritos médicos o un médico designado como tal por un tribunal, que debe poseer un alto grado de sabiduría, práctica, experiencia y habilidad en una ciencia o arte que le permita efectuar, con seguridad sobre los medios o procedimientos utilizados y expresar los resultados de la pericia solicitada, en forma clara y en lenguaje corriente. Cuando no esté en condiciones de llegar a una conclusión categórica, debe expresarlo y señalar las causas. Por ejemplo: hay casos de autopsias MédicoLegales en las cuales, a pesar del apoyo imagenológico y de laboratorio, se concluye «Causa de muerte indeterminada». Los peritos y los expertos deben confeccionar un documento basado en una «Pauta Medico Legal de la Historia Clínica del Lesionado» donde deben dejar constancia de la identificación, los antecedentes, el examen físico segmentario, los exámenes complementarios e imágenes, la evolución clínica, el diagnóstico médico-legal, el pronóstico, la identificación del médico y las observaciones si las hay. Hipotéticamente, si como radiólogos fungiéramos como peritos deberíamos considerar que 
el producto de la atención radiológica consta de dos partes: las imágenes propiamente tales y el informe radiológico. Teniendo esto en cuenta, podríamos desarrollar una especie de «Pauta Médico-Legal de las Imágenes del Lesionado» donde deberíamos consignar si están debidamente identificadas y marcadas, vale decir: no cabe duda que pertenecen al caso analizado, evaluar si su calidad técnica es suficiente para diagnóstico, si las secuencias o cortes empleados en exámenes complejos son los validados por el estado del arte y la práctica, si hay una serie o elección lógica, de acuerdo al cuadro clínico, de las modalidades realizadas y adecuarlas al tiempo, lugar y circunstancia del hecho investigado, teniendo en cuenta que hay técnicas o modalidades que no son diagnósticas ni excluyentes para ciertas patologías y tampoco están disponibles en todos los lugares de atención médica.

En lo que respecta al informe radiológico, lo primero que debemos consignar es si existe o no, si está firmado por radiólogo u otro especialista. El tipo de informe elaborado (estructurado, narrativo, itemizado), no es tan importante como su sujeción a normas, pero en todos los casos en que es posible, la impresión diagnóstica debería fluir lógicamente de lo descrito en el informe.

4. Imputado: La calidad de imputado implica ser sujeto de una investigación para determinar culpabilidad o inocencia en un acto médico o radiológico dado, «resultados adversos» con daños, en que el Tribunal Oral en lo Penal debe determinar, basado en la búsqueda del error, una posible «negligencia médica» teniendo en cuenta que no todo acto médico erróneo puede resultar imprudente, ya que un acto negligente requiere de la concurrencia de varios factores: el primero es que el médico haya efectuado un acto médico, lo que establece un contrato tácito que corresponde a la relación médico-paciente. Para los radiólogos, si no hay relación directa, el informe radiológico y/o las imágenes obtenidas constituyen dicha relación. El segundo, es que se haya producido un daño somático. En tercer lugar, la existencia de una relación de causa a efecto entre la acción u omisión y el resultado lesivo. En cuarto lugar, que no haya un apego a la «Lex Artis»y "State of the Art» para ese sitio, momento y circunstancia en particular ${ }^{(14)}$.

\section{¿De qué delitos puedo ser imputado?}

En líneas muy generales, y sin entrar en rigurosidades jurídicas, los delitos por los cuales un imputado responde, pueden ser simples delitos culposos cuasidelitos. Este último consiste en una acción u omisión con resultado dañoso, sin la intención de provocarlo. En los delitos con dolo, hay la voluntad deliberada de cometerlos a sabiendas de su carácter delictivo.

Los elementos necesarios de la responsabilidad cuasidelictual del médico son: el autor debe ser médicocirujano, el agente debe encontrarse en un acto de ejercicio profesional, la conducta debe causar daño a las personas, el médico debe haber actuado culpablemente y debe existir una relación de causalidad entre el acto culposo y el daño resultante.

Se describen distintos grados o formas de culpa que brevemente serían: imprudencia o hacer más de lo necesario, negligencia o hacer menos de lo necesario, actuar con descuido o falta de cuidado, impericia o insuficiente capacitación para la realización del acto, inobservancia del reglamento o incumplimiento de las normas reglamentarias ${ }^{(16)}$.

En radiología, un mal manejo de las radiaciones ionizantes en un embarazo de primer trimestre con resultado de daño somático, podría ser una conducta imprudente, negligente, producida por impericia, noapego al «state of the art», o sin culpa, dependiendo de las circunstancias que rodeen al acto radiológico, todo ello es decidido por el Tribunal Oral en Io Penal, considerando la opinión de expertos y peritos. Los daños que puede causar la actividad culposa de un médico se pueden dividir en tres clases: perjuicios somáticos, perjuicios pecuniarios, perjuicios morales.

Los daños somáticos tienen que ver con el derecho penal. Para la configuración del cuasidelito debe existir daño somático que se define como "cualquier detrimento o menoscabo de la vida, integridad corporal o la salud del paciente, y debe haber sido causado directamente por el agente, y debe ser real y efectivo, tanto que a no mediar él, el paciente se habría encontrado en mejor situación». Si no existe dicho perjuicio somático en el paciente, a pesar de que el médico hubiera actuado culposamente en el ejercicio de su profesión, no se puede dar por configurado el cuasidelito del artículo 491 del Código Penal.

Los daños morales y pecuniarios son del ámbito del derecho civil. Persiguen obtener una satisfacción económica por el daño causado, de acuerdo a la gravedad de las lesiones y otros parámetros. En estos juicios son demandadas las instituciones prestadoras de salud incluyendo al Estado y sus agentes, al existir una relación contractual tácita entre médicos y pacientes (económica). La relación contractual tácita entre Instituciones y pacientes es válida para todo lo que no haya sido acordado o aceptado por escrito ${ }^{(17)}$.

\section{Solución de Conflictos. Escenario pasado}

Los procedimientos usados en el sistema penal para la solución de conflictos eran: Común Acuerdo y Juicio Penal. Conforme con nuestro ordenamiento jurídico, un juicio de «malpractice» debía iniciarse con una denuncia en materia penal. Posteriormente y de acuerdo al resultado de este procedimiento procedía o no un juicio de responsabilidad civil médica.

El proceso penal se caracterizaba por ser un procedimiento inquisitivo en dos etapas; la primera, era la etapa de sumario que comenzaba con una querella o denuncia, era investigativa y podía tardar años; en ella el Juez investigaba en una primera etapa secreta de sumario, después juzgaba y eventualmente condenaba. El acusado debía avanzar y defenderse a ciegas durante el sumario y el proceso terminaba con 
el sobreseimiento o con la acusación de oficio, donde no había un juicio penal propiamente tal. La segunda, era la etapa de plenario o juicio propiamente tal, que comenzaba con la dictación del auto de procesamiento. Era en esta etapa donde el acusado podía defenderse, con conocimiento de los hechos y, culminaba el proceso con la sentencia.

\section{Solución de Conflictos. El nuevo escenario en la RPP.}

La RPP ha desplegado un nuevo escenario médico-legal para el ejercicio de la Medicina, sumado a la reforma de salud (RS), Nueva Ley del Consumidor, Ley de las ISAPRES, y otras. La solución de conflictos en este nuevo contexto legal podrá ser: de común acuerdo, por mediación, arbitraje, soluciones judiciales alternativas o juicio, que será diferente a los que conocemos.

\section{A. Solución destribunalizada de conflictos}

En el marco de las leyes de RS, la ley 19.937 de Autoridad Sanitaria, que modifica el DL 2.763 de 1979, introduce la mediación y el arbitraje como soluciones previas a los tribunales, cuyo artículo 15 establece «implementar, conforme a la ley, sistemas alternativos de solución de controversias sobre responsabilidad civil de prestadores individuales e institucionales, públicos o privados, originada en el otorgamiento de acciones de salud, sin perjuicio de las acciones jurisdiccionales correspondientes. Los sistemas podrán contemplar la intervención de entidades públicas y privadas que cumplan con condiciones técnicas de idoneidad».

La solución de controversias entre aseguradores y cotizantes será llevada a cabo por la Superintendencia de Salud, a través de la Intendencia de Fondos y Seguros Previsionales de Salud, quien actuará en calidad de árbitro arbitrador, resolverá las controversias que surjan entre las instituciones de salud previsional y el Fondo Nacional de Salud con sus cotizantes o beneficiarios, siempre que quede dentro de la esfera de supervigilancia y control que le compete a la Superintendencia, y sin perjuicio de que el afiliado pueda optar por recurrir a la instancia de mediación o a la justicia ordinaria.

Intentar un acuerdo en caso de conflicto entre los usuarios de salud y quienes prestan los servicios es lo que intentará hacer el nuevo sistema de mediación. En dos organismos distintos, el Consejo de Defensa del Estado para los usuarios del sistema público y la Superintendencia de Salud para los afiliados al sistema privado, las personas podrán reclamar por su derecho a la salud, por daños o posibles negligencias. La mediación es una instancia previa a los tribunales de justicia, dado que es una etapa prejudicial obligatoria. En caso de no haber acuerdo, el afectado puede recurrir a los tribunales.

\section{B. Solución judicial de conflictos: el nuevo proceso penal}

La RPP cambia el proceso penal, no la tipificación de los delitos. Se crea un Ministerio Público, órgano autónomo y jerarquizado de la administración del Estado, encargado de representar ante los tribunales el interés de la sociedad frente a un hecho que compromete gravemente el interés público. Integrado por la Fiscalía o ente acusador; los Juzgados de Garantía, con jueces encargados de velar por los derechos humanos y constitucionales del imputado, razón por la cual al detenerse a una persona, dentro de las 24 horas siguientes se la debe poner a su disposición; de lo contrario, la persona queda en libertad inmediata y no se la puede someter a proceso. Debe además resolver todos los incidentes que se promuevan durante la etapa de investigación y en la etapa de preparación del juicio; la Defensoría Penal Pública es una organización pública, autónoma, supervisada por el Presidente de la República a través del Ministerio de Justicia, de financiamiento estatal, destinada a otorgar una asistencia letrada gratuita al imputado que carezca de defensa. El Juicio Oral propiamente tal, es público y se lleva a cabo frente a un Tribunal Oral en lo Penal, compuesto por tres miembros y es un órgano dependiente del Poder Judicial, ante los cuales se rendirán las pruebas reunidas por el fiscal y son quienes dictarán la sentencia definitiva ${ }^{(1)}$.

La solución de conflictos en este nuevo marco procesal penal, está dada por las soluciones judiciales alternativas y el juicio con características diferentes.

B1. La RPP permite la posibilidad de Acuerdos Reparatorios entre las partes, en los casos en que el Fiscal considere que el hecho no compromete gravemente el interés público, con la anuencia del Juez de Garantía y el proceso termina. Se estima que alrededor de un $70 \%$ a un $75 \%$ de los casos deberían resolverse a través de Soluciones Judiciales Alternativas.

B2. El Juicio oral, la segunda manera de resolver conflictos en Tribunales, se lleva a cabo en el Tribunal Oral colegiado, ante los cuales se rendirán las pruebas reunidas por el fiscal y son quienes dictarán la sentencia definitiva. Esta audiencia se desarrollará en su totalidad en forma oral, de manera continua, y puede prolongarse sucesivamente hasta su conclusión. La ausencia del querellante o de su apoderado da lugar a la declaración de abandono de la querella.

Los testigos deben ser personalmente interrogados, y su declaración no puede ser reemplazada por lectura de actas o registros. Declaran uno a uno bajo interrogatorio de las partes; primero la que lo presente y luego la contraparte.

Los peritos deben exponer brevemente el contenido y conclusión de su informe, y luego son interrogados. Los jueces también pueden proceder a interrogar a testigos y peritos con el fin de aclarar sus dichos.

Hay presentación de pruebas materiales, posterior a las cuales, se ofrecerá la palabra al fiscal, 
al acusador y al defensor para que expongan sus conclusiones. Fiscal y Defensor tienen la posibilidad de replicar las conclusiones planteadas por las demás partes. Luego se le ofrece la palabra al acusado dando por cerrado el debate. Concluido el debate, los miembros del tribunal oral en lo penal se retiran para deliberar en privado debiendo posteriormente pronunciar la sentencia definitiva en la misma audiencia, salvo algunas excepciones, el proceso finaliza, existiendo aún las instancias de apelación a los tribunales superiores ${ }^{(1)}$.

\section{Acciones que se pueden implementar para revertir la situación de conflictividad medico-paciente}

Sin lugar a dudas y a todas luces, este es un marco jurídico mejor que el anterior. Sin embargo, nuestro objetivo al atender a un paciente no incluye causarle daño, pero dado que la medicina es una actividad que se desenvuelve en la incertidumbre, con el riesgo de no poder garantizar buenos resultados en todos los casos, aunque actuemos con la mayor prudencia, dedicación y cuidado, basados en la «lex artis» de la profesión, sin actos imprudentes o temerarios que puedan producir daño, siempre está presente el riesgo de un resultado adverso. Por esta razón, debemos esforzarnos en adecuar mecanismos para disminuir riesgos, vale decir gestionarlos, lo que se basa en la búsqueda y prevención del error tanto en las personas como en los sistemas en que éstas desarrollan su actividad(18).

La lex artis o conjunto de prácticas y principios aceptados por quienes profesan la medicina, la hacen los médicos. Establecer estándares, protocolos y guías clínicas diagnósticas y terapéuticas, con mínimos y máximos razonables, basados en la mejor evidencia disponible, originados por las Sociedades Científicas, actualizados periódicamente, con incorporación de nuevas técnicas fundamentada y controlada, con curva de aprendizaje supervisada, y difundidos ampliamente entre los miembros de la profesión y las instituciones médicas, es una de las aristas de esta prevención. La otra, tiene que ver directamente con el profesionalismo de nuestra práctica y nuestro modo de efectuar el ejercicio médico como individuos: conducta prudente, conocimiento profundo en ciencias y tecnología, discernir y distinguir lo que es bueno o malo, obrar con cautela, moderación, sensatez, buen juicio y enfrentamiento solidario de las dificultades diagnósticas y terapéuticas, así como de las complicaciones. Un tercer grupo de acciones se refiere a propiciar y mantener buenos estándares de calidad en las formaciones de pre y post grado, educación médica continua reglada, acreditaciones universales, restablecer el control ético efectivo por parte de la orden y con él, el prestigio de la profesión ${ }^{(19)}$.

Los radiólogos estamos sujetos a cometer dos grandes tipos de errores, que si producen daño, pueden tribunalizarse. Son los errores de logística como el extravío de placas o imágenes electrónicas, error en identificar derecho o izquierdo, errores en la identificación del paciente etc., es decir, todos aquellos errores que se relacionan con el funcionamiento del Servicio de Radiología, sin relación directa con al acto diagnóstico, pero sí con el acto radiológico del cual también somos responsables. El otro tipo de errores es el que se relaciona directamente con el acto diagnóstico del radiólogo, los errores diagnósticos, que describiremos brevemente por su importancia para el radiólogo y que se manifiesta de varias formas.

Errores diagnósticos: Error de percepción, que constituye el $60 \%$ del total. En este caso, el radiólogo sigue todos los procedimientos y normas adecuadas, fallando en reconocer una anomalía que en retrospectiva le es aparente. ¿En que consisten? Kopans lo describe como «caprichos de percepción, interrupción perceptual ajena a negligencia que correspondería más bien a un fenómeno psicovisual inmutable». Aún no sabemos por qué omitimos, no vemos o no informamos hallazgos radiográficos que en retrospectiva son obvios ${ }^{(20-21)}$. Error de juicio en el cual la imagen es correctamente analizada y deducida pero al momento de formular un diagnóstico se hace un juicio erróneo. Error cognoscitivo que se produce con mayor frecuencia, en las áreas de diagnóstico más especializadas como neuro-radiología, imágenes mamarias, radiología pediátrica, al ser informadas por radiólogos generales, por la falta de habilidades y conocimientos técnicos específicos. Errores en la comunicación de los resultados que ocurren cuando las imágenes y el análisis de los resultados son adecuados, pero la oportunidad de la comunicación falla, con el consiguiente riesgo de retrasar terapéuticas o decisiones urgentes.

Sobre estos aspectos debemos trabajar en prevención para disminuir la conflictividad y posible tribunalización de un evento adverso ${ }^{(22,23)}$.

En el fondo de toda situación que potencialmente pueda derivar en un conflicto incontrolable hay una falla de comunicación entre el equipo médico y los pacientes y su familia. Tal vez por esto, las dos «reglas de oro» de la atención médica que reducen la conflictividad, son la obligación de informar a los pacientes de todas las circunstancias relativas a su enfermedad y las posibilidades de diagnóstico y terapéutica posibles para que el enfermo decida en función de ello, es decir un consentimiento informado real y no pasar por alto que el paciente tiene derecho a elegir entre las alternativas de tratamiento, exámenes o procedimientos que se le ofrezcan (autonomía, que es el principio en que se fundamenta el consentimiento informado) $^{(24)}$.

Los radiólogos, por la organización de su trabajo, no tienen mucha comunicación directa con la mayoría de los pacientes, pero existen dos situaciones en que los principios citados deben ser aplicados fehacientemente: cuando se debe efectuar un procedimiento de radiología intervencional, que debe ser explicado cuidadosamente, incluyendo las posibles alternativas; también cuando un paciente solicita ser informado del resultado de su examen, no olvidemos 
que somos médicos de apoyo y el paciente «pertenece» al médico tratante, situación en la cual es necesario explicar dichos resultados en la forma más cuidadosa posible, dejando siempre en claro que el médico tratante es quien propone, a la luz de todos los antecedentes, los diagnósticos y posibilidades terapéuticas. Como dicha información es verbal, debería ser breve y precisa(25).

Finalmente, deberíamos considerar que todos estos conflictos traducen una falla que no sólo es personal sino que implica también algún grado de defecto en el diseño de los sistemas en los que desarrollamos nuestras tareas. Si esto es cierto, a la responsabilidad personal es necesario adicionar la posible responsabilidad institucional. De la mayor importancia, además, es el registro de nuestras situaciones de conflictividad para una efectiva retroalimentación que realmente nos permita aprender para no repetir de nuevo la misma situación. Esto implica un puente entre los procesos legales y la gestión de riesgos médicos para implementar sistemas de auditorías por pares realmente efectivas y resolutivas para cumplir el objetivo antes indicado(26, 27).

Todas las medidas que podamos implementar deben estar dirigidas a un profesionalismo centrado en los pacientes y en la calidad de la atención médica ofrecida.

\section{Resumen y conclusiones}

La RPP, las leyes de RS y otras conforman un nuevo escenario médico-legal para el ejercicio de la Medicina, en un entorno donde el trabajo médico es radicalmente distinto debido a los cambios producidos en la sociedad, que han motivado la gestión de la atención médica con criterios de mercado, con sistemas de atención en los que se ha producido un deterioro de la relación médico-paciente, la pérdida de la tuición ética por los colegios profesionales, y pacientes con plena conciencia de sus derechos y prontos a exigir reparaciones frente a cualquier acto médico (o radiológico) que consideren los perjudica. Esto ha llevado al escenario actual de la tribunalización de los conflictos médicos, cuyo aumento es alarmante.

Hasta el inicio de la RPP todos los conflictos se resolvían de común acuerdo o en los Tribunales de Justicia, donde los médicos por lo general eran requeridos por la justicia penal por presuntos cuasidelitos. El desarrollo de estos juicios, con múltiples citaciones a declarar ante un actuario y un largo tiempo sin sentencia, la que en la mayoría de los casos era absolutoria es pasado. Historia aparte es el $21 \%$ de los casos que se ventilan en la prensa, lo que casi es una precondena pública ${ }^{(11)}$.

El nuevo marco legal tiene fortalezas y debilidades. Entre las primeras están: a) La división de tareas, con personas o entes independientes encargados de la investigación de la denuncia (fiscalías), de la defensa de los imputados (defensoría pública) y un tribunal de tres jueces que pronuncia la sentencia tras un juicio oral y público. b) La agilización de todo el proceso hasta la sentencia, con plazos predeterminados. c) Reconocimiento explícito de las garantías de las personas. d) Introducción de nuevos mecanismos de soluciones de conflictos: no efectuar la investigación, suspensión condicional del procedimiento, acuerdos reparatorios, procedimiento abreviado. Lo anterior se suma a las soluciones destribunalizadas de los conflictos contempladas en la Ley de Autoridad Sanitaria: mediación y arbitraje para intentar alcanzar un acuerdo entre las partes. Sus desventajas relativas: a) Exposición pública del investigado, con la posibilidad de mediatización de un mayor número de conflictos y b) Escasez de peritos calificados para el tema médico.

En este escenario, deberemos esforzarnos en la prevención del error mediante la implementación de medidas adecuadas, para evitar conflictos y sus consecuencias judiciales. Todas las medidas deben estar basadas en el profesionalismo de nuestra atención a los pacientes y sus dos grandes pilares: calidad técnica de acuerdo al estado actual de los conocimientos, humanidad y calidez en nuestro trato con ellos. Esto sea tal vez una manera de recuperar la confianza de nuestros pacientes, prestigio profesional y revertir la situación de alta conflictividad actual, no hay otro camino para lograrlo.

\section{Bibliografía}

1. Carocca A. Manual. «El nuevo sistema procesal penal». $3^{\text {a }}$ ED. Lexis- Nexis. Santiago. 2005.

2. Singer PA. Recent Advances: Medical Ethics. BMJ 2000; 321: 282-285.

3. Vukusich A, Olivari F, Alvarado N, Burgos M. Causas de la crisis de la profesión médica en Chile. Rev Med Chile 2004; 132: 1425-1430.

4. Irving $\mathrm{DH}$. Time for hard decisions on patient-centered professionalism. Med J Aust 2004; 181: 271-274.

5. Castro JL. Panel: Causas y efectos de los problemas médico-legales. II Seminario Anual de la Asociación de Clínicas. Libro de Resúmenes: 48-53 Santiago. 2000.

6. Horwitz N. El cambio de la práctica médica. Desafíos psico-sociales para la profesión. Rev Med Chile 2004: 132; 768-772.

7. Jiménez JP. Bienestar y satisfacción de los médicos con el ejercicio de su profesión en un sistema de salud en proceso de reforma. Rev Med Chile 2004; 132: 635-636.

8. García C, Ortega D. Avances tecnológicos: la radiología que viene. Rev Med Chile 2002; 130: 699-703.

9. Gunderman RB. The Medical Community's Changing Vision of the Patient: the importance of Radiology. Radiology 2005; 234: 339-342

11. Ciocca L. Jornadas «Responsabilidad legal del médico y su relación con aspectos bioéticos de la medicina». Facultad de Medicina U de Chile. Santiago. 2002.

12. Fundación de Asistencia Legal del Colegio Médico de Chile AG. Resultados 1995-2001. Disponible en www.colegiomédico.cl

13. Montoya D, Rosmanich P, Velásquez V, López J, Aspectos médicos y legales de las querellas por responsabilidad médica. Rev Med Chile 1993; 121: 679-685.

14. Montoya D, Rosmanich P, Velásquez V, López J, Aspectos médicos y legales de las querellas por responsabilidad médica según especialidades en Chile 
Rev Med Chile 1993; 121: 396-402.

15. Bastián R. Experiencia del Instituto Médico-Legal en estudio de las negligencias médicas. II Seminario Anual de la Asociación de Clínicas. Libro de Resúmenes: 1114. Santiago. 2000.

16. García C, Ortega D. El informe radiológico: «Por sus dichos los conoceréis» Rev Chil Radiol 2001; 7: 65-69.

17. Acosta V. Responsabilidad civil médica en Chile. Rev Chil Radiol 1997; 3: 5-17.

18. Sateler R. Panel: Causas y efectos de los problemas médico-legales. II Seminario Anual de la Asociación de Clínicas. Libro de Resúmenes 46-48. Santiago 2000.

19. Martínez FJ, Ruiz JM. Manual de Gestión de riesgos sanitarios. Ed. Díaz de Santos SA. Madrid. 1ª ED. 2001.

20. Barondess AJ. Medicine and Professionalism. Arch Intern Med 2003; 163: 145-149. Kopans DB. Breast Imaging. $2^{\text {nd }}$ ed. Philadelphia: Lippincott-Raven,
1998: 797-798.

21. Berlin L. Perceptual errors AJR 1996; 167: 587- 589.

22. García C. Anatomía del error en radiología. Rev Chil Radiol 2003; 9: 144-156.

23. Szánthó G. Definiciones respecto al error en medicina. Rev. Med Chile 2001: 129: 1466-1469.

24. Gracia D. Fundamentos de bioética. Madrid: EDEMA, 1989; 505-506.

25. García C, Ortega D. Comunicación en el departamento de radiología: Radiólogos y pacientes. Rev Chil Radiol 2003; 3: 151-156.

26. Szánthó G. Panel: Causas y efectos de los problemas médico-legales. II Seminario Anual de la Asociación de Clínicas. Libro de Resúmenes 53-58. Santiago. 2000.

27. Rencoret G. Auditoría Médica:Demandas y responsabilidad por negligencias médicas. Gestión de calidad: Riesgos y conflictos. Rev Chil Radiol 2003; 9: 157-160.

\section{APENDICE: Recomendaciones Prácticas en el Manejo de la Tribunalización en Radiología}

Las medidas preventivas para minimizar los eventos adversos tribunalizados ya fueron tratadas en una publicación anterior ${ }^{(22)}$.

Una vez producida la demanda o querella pensamos que considerar algunos de los puntos enumerados a continuación pudieran ser de utilidad.

Mantener la calma. La demanda presentada va a ser por cuasidelito de lesiones o de homicidio, vale decir del ámbito penal. Esto no significa que el demandante quiera ejercer una acción penal en su contra: por regla general, busca una compensación monetaria y para poder entablar una acción por responsabilidad civil médica, de acuerdo a nuestro ordenamiento jurídico, debe pedir primero una acción penal, donde es necesario demostrar la culpabilidad del demandado para seguir con la acción civil. Es a la vez una medida de presión efectiva sobre el demandado.

Tratar de averiguar qué es lo que realmente quiere el paciente o su familia, en el caso de lesiones o secuelas. ¿Una solución para el problema? ¿Dinero? Considerar que el error siempre existe, aun con los mejores resguardos, al igual que los pacientes o familiares descontentos con un resultado médico inesperado y que recurren a los tribunales.

Recordar que es el tribunal, asesorado con peritos médicos, quien determina si la acción médica cuestionada se debe a una negligencia o a un curso evolutivo diferente al esperado.

En espera de la resolución, tener presente que en el $75 \%$ de las demandas por negligencia médica (Responsabilidad Civil Médica) el resultado es favorable al médico, sin demostrarse que hubo negligencia.

Buscar siempre asesoría médico-legal y legal propiamente tal, ya sea a través de FALMED, un seguro de responsabilidad médico civil (RCM) contratado individual o colectivamente o, con un abogado independiente, quien debería tener experiencia en juicios de negligencia médica.

Sabemos que existen posiciones contrapuestas con respecto a contratar los seguros de RCM. FALMED es una fundación sin fines de lucro que sirve a los colegiados que se inscriben en esa fundación. Aun en el caso de tener seguros privados contratados es altamente recomendable recurrir precozmente a FALMED.

Una vez obtenida la asesoría legal y conocido el caso por el cual somos demandados, los profesionales de la ley, de acuerdo al resultado del análisis del caso y sus resultados, nos propondrán el curso de acción, a su juicio, más adecuado, el que puede ser reconocer la responsabilidad y alcanzar un acuerdo reparatorio o algunas de las soluciones judiciales alternativas.

En caso contrario, ir al juicio oral público, para la defensa de la causa. Debemos estar preparados para la exposición pública, con interrogatorios «agresivos» de la parte demandante y la posible mediatización del proceso.

Recordar que aun cuando los abogados son los expertos en estos temas y su manejo, quien debe tomar la decisión final del curso de acción a seguir es el demandado, considerando todas las alternativas propuestas y el consejo legal proporcionado y su convicción personal del caso.

Si el resultado del juicio oral es adverso, y nuestro consejero legal coincide con nosotros en la necesidad de una apelación, ésta puede ser presentada a un tribunal superior.

Estar preparados para los costos emocionales de los juicios, tanto personales como familiares. 